\title{
INVESTIGATION OF MORPHOLOGICAL AND ANATOMICAL CHANGES IN CATHARANTHUS ROSEUS (L.) G. DON DUE TO COLCHICINE INDUCED POLYPLOIDY
}

\author{
A.Y. Shala* and Z. Deng ${ }^{* *}$ \\ * Medicinal and Aromatic Plants Research Department, Horticulture Research Institute, \\ Agricultural Research Center, Giza, Egypt. \\ ** Department of Environmental Horticulture, Gulf Coast Research and Education Center, \\ University of Florida, USA.
}

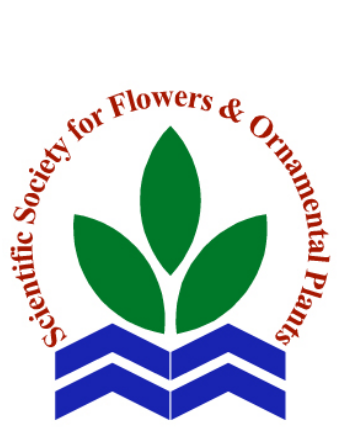

Scientific J. Flowers \& Ornamental Plants, 5(3):233-243 (2018).

Received: 9/9/2018

Accepted: 20/9/2018
ABSTRACT: Catharanthus roseus (L.) G. Don is valuable medicinal plant grown as an ornamental plant. The study was carried out at Gulf Coast Research and Education Center, University of Florida, USA. to evaluate the morphological and anatomical changes from induced polyploidy in periwinkle for this purpose colchicine was applied at four different concentrations $0.0,0.05,0.1$ and $0.2 \%$ for seedling treatment. The results showed that raising colchicine doses caused an increasing of survival percentage and tetraploid plants number. Polyploids showed an increment in leaf thickness, stomatal size, pollen diameter and pollen viability compared to diploid plants. Flow cytometry verified the existence of tetraploids and mixoploids from various colchicine-treated plants especially 0.2 which was found efficient on inducing polyploidy in the plants followed by $0.1 \%$ as compared to other concentration under study.

Key words: Vinca, chromosome doubling, colchicine, nuclear DNA content, tetraploid.

\section{INTRODUCTION}

Catharanthus roseus (L.) G. Don is a perennial plant from Apocynaceae Family and is generally identified as the Madagascar periwinkle. It was originally classified as Vinca rosea by Linnaeus, and later renamed as Catharanthus roseus built on their morphological features (Van Der Heijden et al., 2004). Physiologically it produces important antineoplastic alkaloids such as vincristine and vinblastine, which are chiefly existing in the leaves, while antihypertensive alkaloids (ajmalicine, serpentine and reserpine) are located in roots (Mishra et al., 2001). Leaves of C. roseus are utilized for the therapy of menorrhagia, rheumatism, dyspepsia, indigestion, dysmenorrheal, diabetes, hypertension, cancer, menstrual disorders, skin diseases, bleeding, diarrhea and antiviral properties (Farnsworth et al., 1968 and Holdsworth, 1990). It is grown as a decorative plant in gardens and parks for its different colored flowers and blooming nature. The wild type of $C$. roseus is a diploid $(2 \mathrm{n}=16 ; 1500 \mathrm{Mbp}=12 \times$ Arabidopsis thaliana genome) plant (Levêque et al., 1996).

Chromosome doubling is a beneficial implement in horticulture for gaining beneficial features, such as strong growth, bigger and extra heavily textured flowers, longer or delayed flowering period, and higher levels of resistance to disease (Hilu, 1993; Rose et al., 2000; Väinölä, 2000; Shao et al., 2003 and Zhang et al., 2008). Also, polyploid plants can be more vigorous, have thicker leaves, bigger fruit, a better degree of drought and disease tolerance, enhanced adaptability, and endurance to environmental stress (Chakraborti et al., 1998 and Eeckhaut et al., 2004). Furthermore, chromosome doubling might offer an opportunity for 
novel phenotypic differences causing from gene duplications (Udall and Wendel, 2006).

Chemicals utilization to produce variations in chromosome number has been well established (Thao et al., 2003 and Jaskani et al., 2005). Moreover, many inhibitors can be applied to block cell cycle progression in cycling plant cells, such as the anti-mitotic drug, one of these is colchicine that used to generate impeding at metaphase of mitosis. Colchicine is an alkaloid isolated from Colchicum autumnale L. which acts by binding to the tubulin dimmers inhibiting microtubules establishment and consequently, spindle fibers during cell division (Petersen et al., 2003). In addition, it is a conventional polyploidy producing compound, which effectively used to produce polyploidy by stopping mitosis at the anaphase period (Thao et al., 2003).

Stomata of polyploids are generally larger (Griesbach and Bhat, 1990 and Kadota and Niimi, 2002), and are one of an easy diagnostic trait that is often used to identify potential polyploids. Furthermore, this technique is rapid, inexpensive, and nondestructive, does not require advanced equipment, and has a fairly high accuracy rate (up to 90\%) in some cases (Cohen and Yao, 1996) conversely, it is an indirect way for ploidy evaluation. If mixoploid plants are, formed in that case stomatal size can be an inaccurate way and should be joined with another method (Chen et al., 2006). Chromosome counts are possibly the best precise, and aneuploidy might be discovered, while this technique can be laborious if many plants are being tested.

Analysis of DNA content by flow cytometry is often desired, many thousands of cells can be investigated quickly, mixoploids can be promptly distinguished. In some cases, for instance, in genome doubling from wide hybridization, genomic rearrangement can lead to changed genome size and complicate interpretation of ploidy based on DNA content (Levin, 2002). In addition, flow cytometry needs buying of costly apparatus, at the same time chromosome performance cannot be detected with this method.

The aim of this study was to find a suitable level of colchicine that would effectively induce maximum polyploids in Catharanthus roseus (L.) G. Don from diploid plant, characterize the morphological and anatomical changes and determine the nuclear DNA content of newly induced tetraploid Vinca.

\section{MATERIALS AND METHODS}

Vinca seeds cv. Vinca Little Bright Eye were brought from Neseed Company 3580 main street, Hartford CT 06120 (its website is http://www.neseed.com/aboutus.asp) then were sown on Apr. $1^{\text {st }} 2015$ and grown in a greenhouse at the University of Florida, Gulf Coast Research and Education Center, Wimauma, Florida, USA. into 128-celled trays containing Fafard 3B Mix, the components of the mix were Canadian sphagnum peat $(50 \%)$, processed pine, bark, perlite and vermiculite.

\section{Colchicine treatment and polyploidy production:}

Following 10 days of germination in the greenhouse, four concentrations of colchicine (Austratec Pty. Ltd) (0.0, 0.05, 0.1 and 0.2 percent) were used. An amount of $15 \mu 1$ of colchicine solution was applied to each seedling on three consecutive days. The colchicine solution was containing $1 \mathrm{ml}$ semi-solid agar and $0.2 \%$ dimethyl sulphoxide (DMSO) to increase cell permeability and absorption of colchicine. Measurements of survival percentage were determined two times, four and eight weeks after colchicine treatment by counting the number of survival seedlings per treatment.

\section{Polyploidy analysis:}

Selection of tetraploid plants was done on the basis of morphology, followed by a selection on the size of stomata, pollen viability and diameter and finally flow cytometry. 


\section{Leaf area determination:}

Leaf area was measured by scanning leaves using leaf area measurements software while, leaf thickness was measured with an electronic caliper.

\section{Stomata length:}

Diploid and tetraploid plants leaves were removed and a small piece of the lower epidermis was peeled off (the stomata were separated by removing a thin layer from the lower side of leaves and studied under a microscope). Each leaf peel was placed in a drop of water on a glass slide, coated with a cover slip, then used for measuring stomata length under a light microscope (Olympus BX41, Canada Q- Color-5, Cooled, RTV) by using $40 \mathrm{X}$ objective magnification, (Stomatal size was measured in micrometers by evaluating the length and width of stomata). The stomata were photographed with an M Eye Digital camera and measured using Vision Explore software (Q Capture Pro).

\section{Pollen viability and diameter:}

For evaluation of pollen viability, pollens were collected from opened flowers for diploid and tetraploid plants. Pollens were stained with $40 \mathrm{~mL}$ of fluorescein diacetate (FDA, Sigma-Aldrich, St. Louis, $\mathrm{MO})$. FDA solution containing $10^{-6} \mathrm{M}$ FDA and $0.25 \mathrm{M}$ sucrose and incubated at room temperature for a least $60 \mathrm{~min}$ in the dark. Stained pollen was located on a glass slide and coated with a coverslip. Pollen grains were scanned utilizing a fluorescence microscope (Olympus BX 41). Consistently round, non-wrinkled, brilliantly fluorescing pollen grains were deemed viable while, non-fluorescing or delicately fluorescing and wrinkled or twisted pollen grains were deemed non-viable. Pollen diameter was measured in micrometers by placing the scale end to end along the diameter of pollen grains. Pollens were photographed with an $M$ Eye Digital camera and measured using Vision Explore software (Q Capture Pro). Diploid pollen viability was observed at $10 \times$ lens while tetraploid pollen was observed at
$4 \times$ lens under a fluorescence microscope (Olympus BX 41).

\section{Flow cytometry:}

Ploidy levels were screened by using flow cytometry (Cube 6 Flow Cytometry, Germany). Leaf squares of approximately $0.5 \mathrm{~g}$ were cut from edges of the newly matured leaves, placed in a $55 \mathrm{~mm}$ diameter plastic petri dish along with $1.0 \mathrm{ml}$ nuclei extraction buffer (LB01 lysis buffer ), and chopped using a razor sharp edge into pieces. The contents of the petri dish were then filtered (pore size $=50 \mathrm{~mm}$ ) into a $3.5 \mathrm{ml}$ test tube to which $0.5 \mathrm{ml}$ of staining buffer (propidium iodide, $1 \mathrm{mg} / 1$ ) and $0.5 \mathrm{ml}$ of Rnase was added and kept in darkness for 10 min. The flow cytometer's gain value was set at 490.0 and speed was set at $0.40 \mathrm{ml} \mathrm{s}^{-1}$. The standard peak of a known diploid Vinca was calibrated to appear at approximately 100 of fluorescence intensity (channel number) and histograms of DNA content were generated by using the Partec software package. To determine genome size Glycine max cv. Polanka, with a known DNA content of $2 \mathrm{C}=2.50 \mathrm{pg}$, was utilized as an internal standard to verify relative genome size that was done by flow cytometry.

\section{RESULTS}

\section{Survival percentage:}

Higher colchicine concentrations tended to have greater survival percentage (Table, 1). The highest colchicine concentration $(0.2 \%)$ recorded the best survival percentage $(55.4 \%)$ while, the survival percentage sharply declined as colchicine rate decreased.

\section{Morphological changes:}

In all morphological observations, colchicine concentration had a marked influence on the treated plants growth accordingly, control plants were taller than colchicine treated plants also, tetraploids had more branches than diploids (Fig., 1). Moreover, tetraploid had smaller and thicker 
Table 1. Effect of colchicine concentrations on survival percentage of Catharanthus roseus (L.) G. Don plants.

\begin{tabular}{lccc}
\hline Treatments & $\begin{array}{c}\text { Number of plants before } \\
\text { the treat. }\end{array}$ & $\begin{array}{c}\text { Survival (\%) after one } \\
\text { month }\end{array}$ & $\begin{array}{c}\text { Survival (\%) after two } \\
\text { months }\end{array}$ \\
T0 & 89 & $59(66.0 \%)$ & $59(66.0 \%)$ \\
Colchicine (0.05\%) & 84 & $22(26.0 \%)$ & $22(26.0 \%)$ \\
Colchicine (0.1\%) & 82 & $40(48.7 \%)$ & $40(48.7 \%)$ \\
Colchicine (0.2\%) & 92 & $53(57.6) \%$ & $51(55.4 \%)$ \\
\hline
\end{tabular}

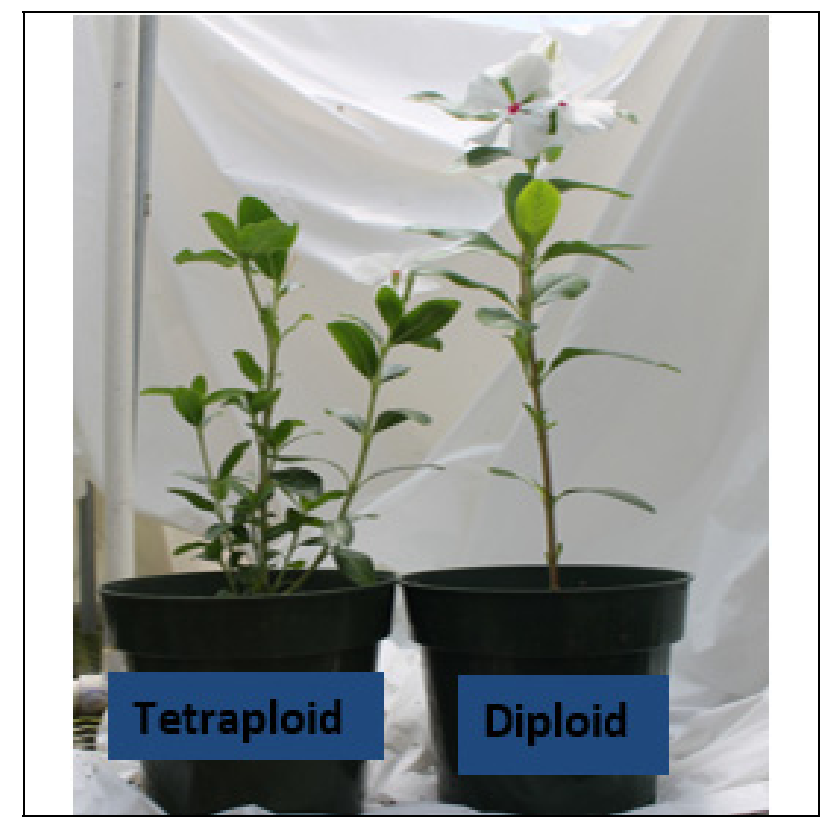

Fig. 1. Diploid and tetraploid Catharanthus roseus (L.) G. Don plants.

leaves therefore, leaf area of tetraploid was smaller than diploid plants (Table, 2).

\section{Stomata observation:}

Stomata size showed significant differences among diploid and tetraploid plants consequently, mean of control stoma length was $18.82 \pm 1.77 \mu \mathrm{m}$ and $16.64 \pm 2.26$ $\mu \mathrm{m}$ for width (Table, 2 and Fig., 2) while, mean stoma for tetraploid plants was
$28.59 \pm 3.74$ and $21.87 \pm 2.80 \mu \mathrm{m}$ for length and width respectively.

\section{Pollen diameter and pollen viability:}

There was a clear difference between pollen sizes in colchicine-treated plants and non-treated ones (Table, 3 and Fig., 3) accordingly, the greater part of tetraploid pollen grains were larger than diploids pollen grains. Tetraploid and diploid pollen diameter were $64.57 \pm 3.22$ and $59.41 \pm 1.67$ $\mu \mathrm{m}$, respectively. Otherwise, the results showed pollen viability differences among diploid and tetraploid plants (Table, 3 and Fig., 4) hence, tetraploid plants had the highest pollen viability percentage $(64.0 \%)$ comparing with diploids, which had the moderate average pollen viability percentage $(55.0 \%)$.

\section{Flow cytometry analysis:}

Screening of 106 plants by flow cytometry ascertained that 62 treated plants were diploid while, 31 treated plants were tetraploid and 13 were mixoploid (Table, 4). Histograms with excitation peak of fluorescent intensity at channel 100 matched by diploids (Fig., 5A) and channel 200 corresponded to tetraploids (Fig., 5B).

Table 2. Morphological characteristics of diploid and tetraploid Catharanthus roseus (L.) G. Don plants (mean \pm SD).

\begin{tabular}{ccccc}
\hline \multirow{2}{*}{ Ploidy } & $\begin{array}{c}\text { Leaf thickness } \\
(\mathbf{m m})\end{array}$ & Leaf area $\left(\mathbf{c m}^{\mathbf{2}}\right)$ & \multicolumn{2}{c}{ Stoma size $(\boldsymbol{\mu m})$} \\
& & & Length & Width \\
\hline $\mathbf{2} \mathbf{x}$ & $0.25 \pm 0.02$ & $14.33 \pm 1.95$ & $18.82 \pm 1.77$ & $16.64 \pm 2.26$ \\
$\mathbf{4} \mathbf{x}$ & $0.32 \pm 0.02$ & $10.58 \pm 1.45$ & $28.59 \pm 3.74$ & $21.87 \pm 2.80$ \\
\hline
\end{tabular}




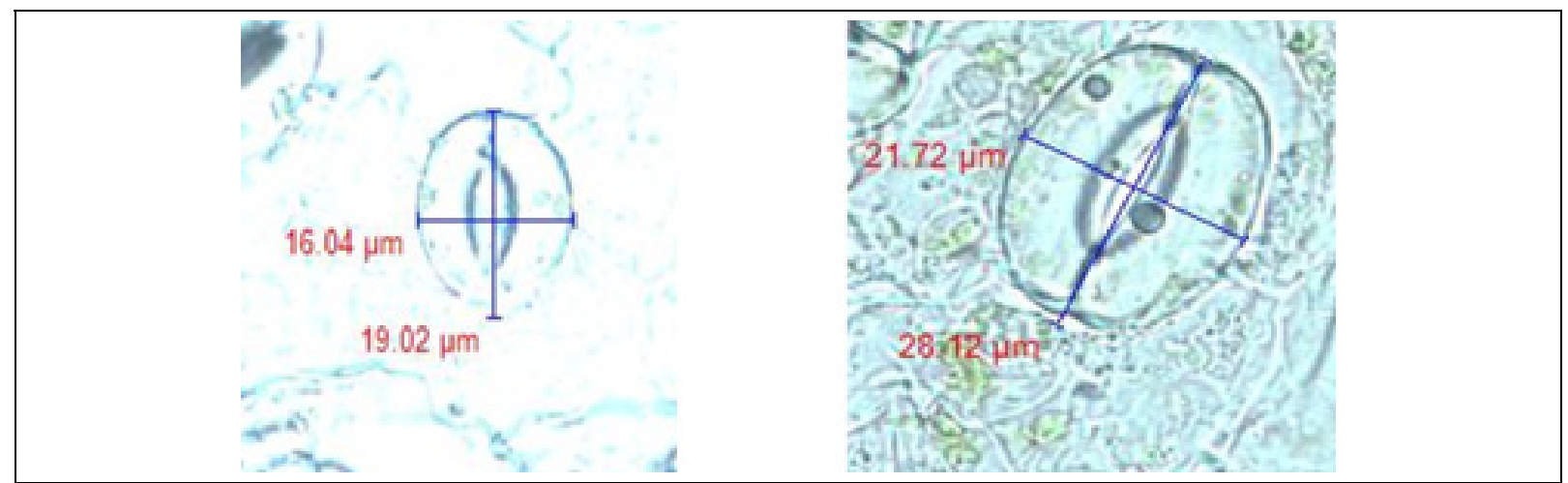

Fig 2. Stoma size in Catharanthus roseus (L.) G. Don diploid plant left, tetraploid plant right.

Table 3. Pollen diameter and pollen viability percentage of diploids and induced tetraploids of Catharanthus roseus (L.) G. Don plants (mean \pm SD).

\begin{tabular}{cccc}
\hline \multirow{2}{*}{ Ploidy } & \multirow{2}{*}{ Pollen diameter $(\boldsymbol{\mu m})$} & \multicolumn{2}{c}{ Pollen viability \% } \\
& & Viable & Non-viable \\
\hline $\mathbf{2 x}$ & $59.41 \pm 1.67$ & $55.0 \%$ & $45.0 \%$ \\
$\mathbf{4 x}$ & $64.57 \pm 3.22$ & $64.0 \%$ & $35.8 \%$ \\
\hline
\end{tabular}

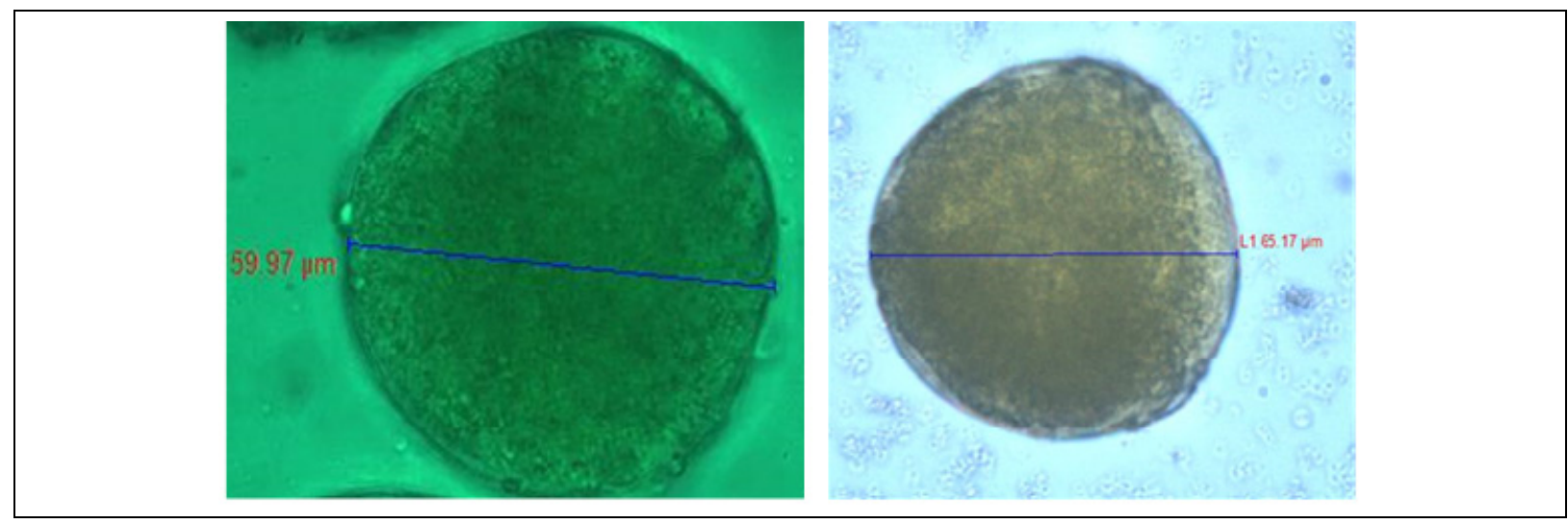

Fig. 3. Pollen size in Catharanthus roseus (L.) G. Don diploid plant right, left tetraploid plant.

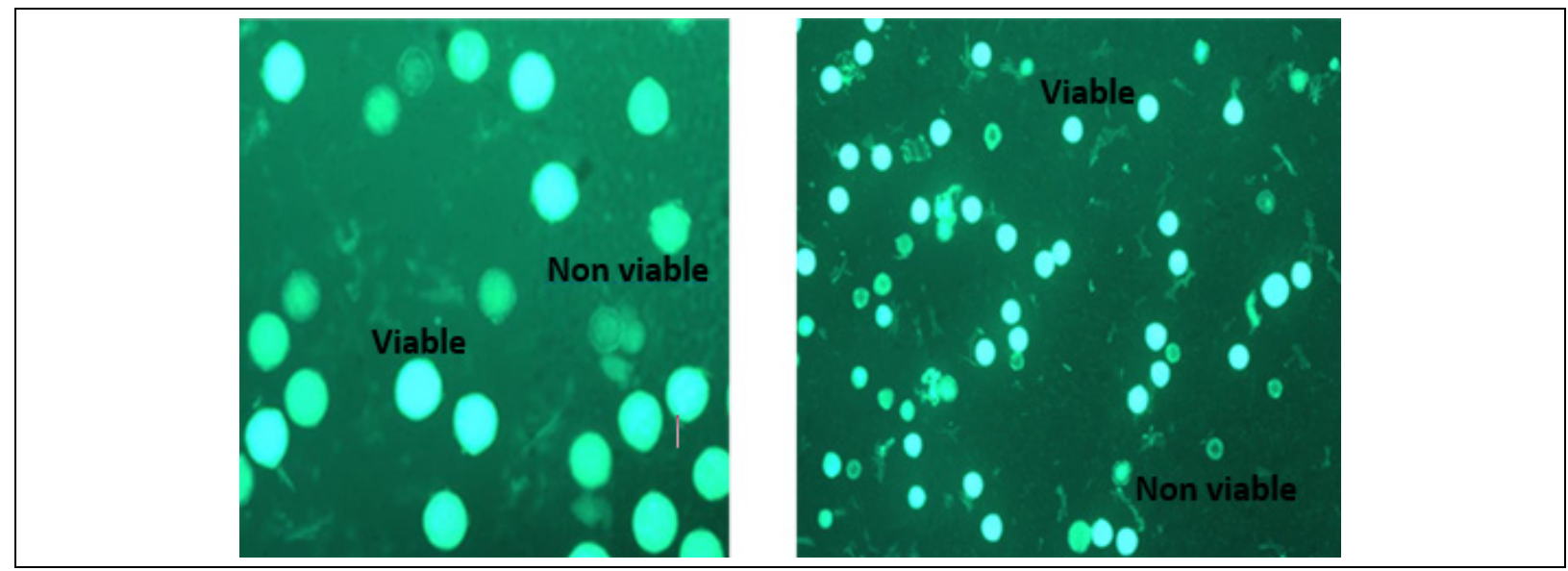

Fig. 4. Viable and nonviable pollen in Catharanthus roseus (L.) G. Don diploid plant left, tetraploid plant right. 
Table 4. Effects of colchicine concentrations on ploidy level of Catharanthus roseus (L.) G. Don plants.

\begin{tabular}{lcccc}
\hline Treatments & $\begin{array}{c}\text { Plants number } \\
\text { before screening }\end{array}$ & $\begin{array}{c}\text { Diploid plants } \\
\text { No. }\end{array}$ & $\begin{array}{c}\text { Tetraploid } \\
\text { plants No. }\end{array}$ & $\begin{array}{c}\text { Mixoploid } \\
\text { plants No. }\end{array}$ \\
\hline T0 & 59 & 59 & - & - \\
Colchicine (0.05\%) & 19 & 15 & 3 & 1 \\
Colchicine (0.1\%) & 40 & 23 & 12 & 5 \\
Colchicine (0.2\%) & 47 & 24 & 16 & 7 \\
\hline
\end{tabular}

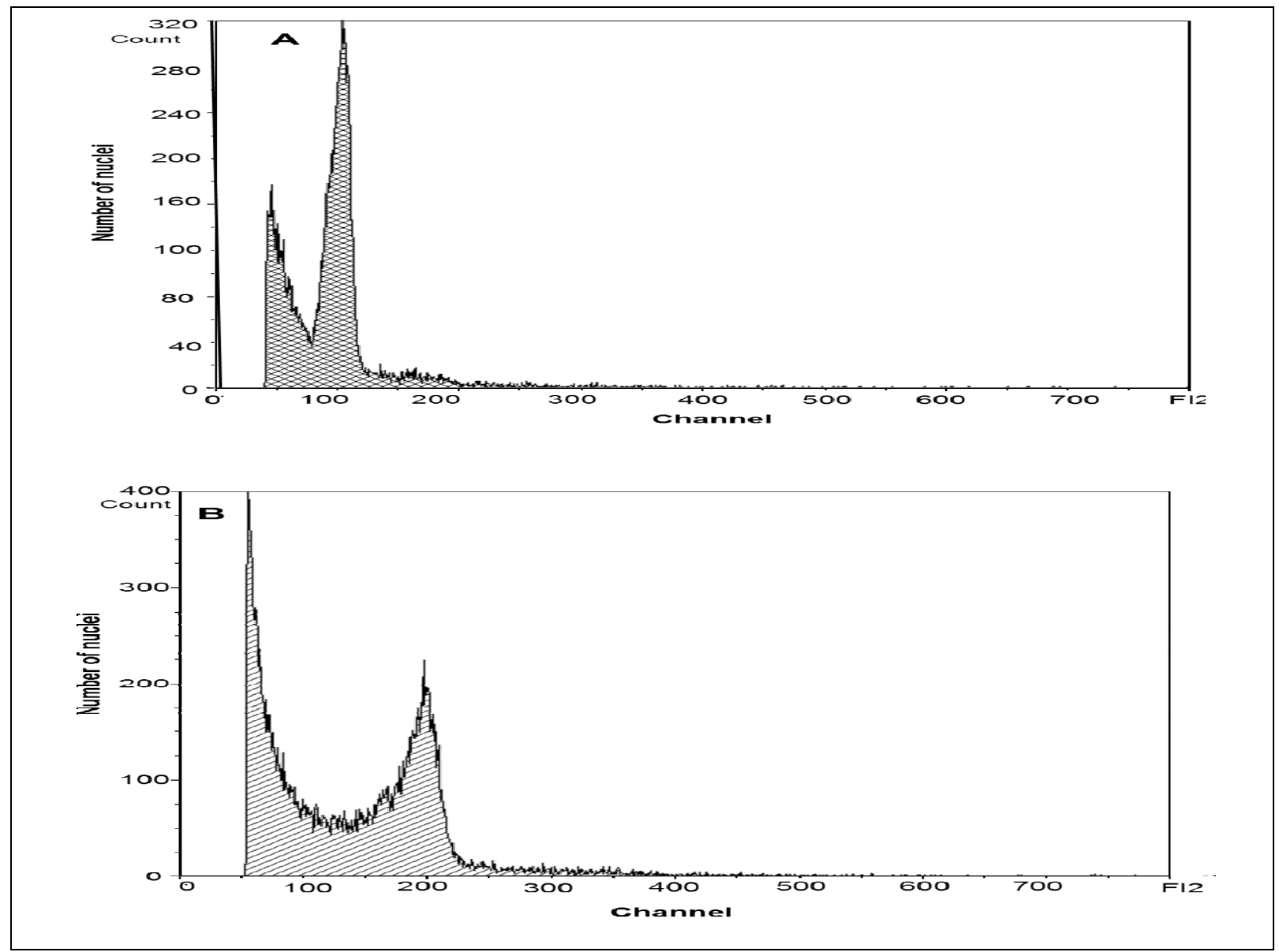

Fig. 5. Flow cytometry histogram of (A) an untreated (control) Catharanthus roseus (L.) G. Don. The diploid peak is fixed at channel 100, (B) tetraploid peak is observed at channel 200.

The number of transplants that were tetraploids and mixoploid containing both diploid and tetraploid cells increased as colchicine rate increased (Table, 4), accordingly, all colchicine concentration produced tetraploid plants, however colchicine at $0.2 \%$ produced more tetraploids and mixoploids number than all other treatments. Therefore, these data recommend that colchicine concentrations at $0.2 \%$ followed by $0.1 \%$ were the optimum concentration under the conditions of this experiment for induction of tetraploidy in Vinca transplants.

\section{Ploidy confirmation:}

Tetraploids of Catharanthus roseus (L.) $\mathrm{G}$. Don had a mean genome size of $2 \mathrm{C}=$ $3.09 \pm 0.04(\mathrm{SD})$, which is approximately twice that of the genome size of diploid Catharanthus roseus (L.) G. Don, $2 \mathrm{C}=1.57$ \pm 0.02 (SD). 


\section{DISCUSSION}

This study displayed that Vinca tetraploids could be induced by treating plant tips with colchicine at concentrations of $0.05,0.1$ and $0.2 \%$, respectively. Usage of colchicine at $0.2 \%$ on the plant tips increased survival percentage and produced more tetraploids than all other colchicine concentrations while other concentrations significantly reduced survival compared with untreated plants. Our findings were in harmony with Marzougui et al. (2011) who applied an aqueous solution of $0.5 \%$ colchicine on Trigonella foenum- graecum L. populations between the two cotyledons for three days per each population as resulted in a significant increment in survival percentage. Conversely, our outcomes were not consistent with the results of Henny et al. (2009) on Dieffenbachia who reported that shoot clumps survival considerably declined as colchicine concentrations increased also, Oates et al. (2012) found that survival of Rudbeckia diploid hybrid genotypes ranged from $0 \%$ to $82 \%$ without any improvement in the allotetraploid hybrids.

The growth of colchicine-treated plants was slower than control. The delayed growth was due to a reduced rate of cell division caused by colchicine for that reason Vinca shoot length decreased (Fig., 1). Similar observations in which the average of shoot length decreased due to initial retardation of growth by colchicine application on Impatiens patula Craib (Tharawoot et al., 2012), Echinacea purpurea L., (Abdoli et al., 2013) and Brassica campestris L. (Kumar and Dwivedi, 2014) that plant height was lower in tetraploid plants related to diploid untreated plants. (Shao et al., 2003) illustrated that during polyploidy induction process, plants are seriously injured, prohibiting normal growth or even killing the plants, depending on the concentrations of colchicine and the period of the treatment.

In the present study colchicine induction in Vinca produced tetraploid significantly different in leaf area and leaf thickness (Table, 2).These results were in harmony with those of Tharawoot et al. (2012) on Impatiens patula Craib who found that tetraploid plants had the highest average of leaf thickness than diploid plants, Kumar and Dwivedi, (2014) found a reduction in leaf length and leaf breadth of Brassica campestris L. tetraploid and Iannicelli et al. (2016) reported that tetraploid displayed considerable changes from the field mother plant in size of Lippia integrifolia leaves. Similarly, the increment in the mean length and width of the stomata of tetraploid plants than in diploid plants (Table, 2 and Fig., 2) hence, stomata size is another source of data which can be used as a tool for primarily verify the status of tetraploid. This is in agreement with the results on mulberry (Chakraborti et al., 1998), Dieffenbachia $\times$ 'Star bright M-1, (Henny et al., 2009), Catharanthus roseus (L.) G. Don (Xing et al., 2011), Tagetes erecta (Sajjad et al., 2013), Echinacea purpurea L. (Abdoli et al., 2013) and Brassica campestris L. (Kumar and Dwivedi, 2014) that, stomata in polyploids are larger than diploids consequently, stomata size can be utilized to reveal the ploidy of Vinca plants. Accordingly, changes in leaves anatomical properties that generally associate with ploidy in plants due to the increment in cell size (Dwivedi et al., 1986) are commonly operated to evaluate polyploidy induction in plants.

The broad literature on phenotypic influences on polyploidy has been studied by Ramsey and Schemske (1998). Transitions to polyploidy are joined by physical changes in the size and geometry of cells, which in turn may involve biochemistry, development, anatomy and ultimately whole-plant morphology, growth and physiology. Therefore, many of the gigas traits of polyploids, such as enlarged cell size, expanded floral structures, stronger foliage and vigorous stems, may be a direct result of increased DNA content (Randolph, 1941). Moreover, having more chromosomes may also slow mitotic division and consequently result in the lower overall growth of the whole plant (Ramsey and Schemske, 2002). 
The increase in the size of Vinca pollen diameter (Table, 3 and Fig., 3) was documented in the present study which agrees with previous observations of Abdoli et al. (2013) on Echinacea purpurea (L.) who found that the diameter of tetraploid pollen grains was considerably larger than those in the corresponding diploid plants, Kumar and Dwivedi (2014) applied aqueous solution of colchicine of $0.3,0.4,0.5,0.6 \%$ to Brassica campestris L. seedlings and found that pollen diameter in autotetraploid and diploid plants was $67.95 \pm 0.02$ and $26.05 \pm 0.28 \mu \mathrm{m}$, respectively and Iannicelli et al. (2016) exposed Lippia integrifolia explants to $0.01 \%$ of colchicine and obtained differences in pollen grains size between the new tetraploids and the diploids. In addition, our results displayed the increment in tetraploid pollen viability percentage (Table, 3 and Fig., 4) over diploid, which consistent with Oates et al. (2012) on in vitro treated shoot apices with $30 \mathrm{mM}$ oryzalin for 5 days as increased pollen staining of allotetraploids of Rudbeckia subtomentosa compared to their diploid counterparts. Likewise, Adaniya and Shirai (2001) stated that all induced ginger tetraploid strains showed higher pollen fertility than original diploid, which may be due to the differences in the types and frequencies of chromosome aberrations (Adaniya and Shoda, 1998).

The results displayed that high colchicine concentration increased proportions of mixoploids in Vinca among the population of diploids and tetraploids (Table, 4) which were in agreement with the previous reports by Henny et al. (2009) who stated that higher levels of colchicine tended to produce mixoploids in Dieffenbachia, Tharawoot et al. (2012) applied colchicine at $0,0.03,0.05$ and $0.09 \%$ on shoots explants of Impatiens patula with the average length of $3 \mathrm{~cm}$ and found that mixoploid plants produced only from the treatment with $0.03 \%$ colchicine. Similarly, Bagheri and Mansouri, (2015) demonstrated that the maximum mixoploids proportion in Cannabis sativa L. was obtained from shoot tips treated with colchicine for $24-\mathrm{h}$ in 0.2 and $0.1 \% \mathrm{w} / \mathrm{v}$. Increasing production of mixoploids could be legitimized by the fact that the antimitotic agent cannot influence all meristematic cells at the time of treatment.

Flow cytometry is a beneficial instrument in confirming ploidy level of Vinca transplants (Table, 4). The advantage of this procedure is simple, rapid, efficient and convenient more than 20 leaf samples can be carried out in $1 \mathrm{~h}$ to confirm Vinca ploidy levels. Due to the expense of running an enormous number of samples, reducing sample size based on morphology can greatly lessen flow cytometry screening costs and increase tetraploids identification chances so, for accurate ploidy level identification of Vinca plants flow cytometry is highly recommended. Furthermore, the morphological markers can also be utilized to accurately confirm the ploidy.

\section{CONCLUSION}

Tetraploid plants of C. roseus (L.) G. Don were gained from colchicine-treated plants. The tetraploid plants have different morphological and anatomical features than those original diploid plants. Tetraploid plants have shorter stems, smaller and thicker leaves as well as exhibited much larger stomata size, pollen diameter and increment of pollen viability than diploid plants and the previous characters were very effective for assessing the ploidy in Vinca plants. It might be worthy to recommend that colchicine could be utilized to raise possible fertile tetraploid Vinca plants, flow cytometry to be used for accurate identification of ploidy level in C. roseus (L.) G. Don. Due to the beneficial medicinal importance of C. roseus (L.) G. Don and the useful outcomes of polyploidy on secondary metabolite yield, additional research is required to determine in detail the effect of polyploidy on alkaloid accumulations of $C$. roseus plants.

\section{Acknowledgment:}

The first author likes to appreciate Dr. Deng's Lab Staff Members at Gulf Coast Research and Education Center, the 
University of Florida for hosting and helping him to finish this work. He is also, grateful to Egyptian Ministry of Higher Education for giving him a scholarship to Florida University

\section{REFERENCES}

Abdoli, M.; Moieni, A. and Badi, H.N. (2013). Morphological, physiological, cytological and phytochemical studies in diploid and colchicine-induced tetraploid plants of Echinacea purpurea (L.). Acta Physiol. Plant., 35(7):2075-2083.

Adaniya, S. and Shirai, D. (2001). In vitro induction of tetraploid ginger (Zingiber officinale Roscoe) and its pollen fertility and germinability. Sci. Hortic., 88(4):277-287.

Adaniya, S. and Shoda, M. (1998). Meiotic irregularity of ginger (Zingiber officinale Roscoe). Chromosom. Sci., 2(3):141144.

Bagheri, M. and Mansouri, H. (2015). Effect of induced polyploidy on some biochemical parameters in Cannabis sativa L . Appl. Biochem. Biotechnol., 175(5): 2366-2375.

Chakraborti, S.P.; Vijayan, K.; Roy, B.N. and Qadri, S.M.H. (1998). In vitro induction of tetraploidy in mulberry (Morus alba L.). Plant Cell Rep., 17:799-803.

Chen, L.; Wang, Y. and Zhao, M. (2006). In vitro induction and characterization of tetraploid Lychnis senno Siebold et Zucc. HortSci., 41(3):759-761.

Cohen, D. and Yao, J.L., (1996). In vitro chromosome doubling of nine Zantedeschia cultivars. Plant Cell. Tissue Organ Cult., 47(1):43-49.

Dwivedi, N.K.; Sikdar, A.K.; Dandin, S.B.; Sastry, C.R. and Jolly, M.S. (1986). Induced tetraploidy in mulberry I. Cytologia (Tokyo). 51(2): 393-401.

Eeckhaut, T.G.R.; Werbrouck, S.P.O.; Leus, L.W.H.; Van Bockstaele, E.J. and Debergh, P.C. (2004). Chemically induced polyploidization in Spathiphyllum wallisii Regel through somatic embryogenesis. Plant Cell, Tissue and Organ Cult., 78(3):241-246.

Farnsworth, N.R.; Svoboda, G.H. and Blomster, R.N. (1968). Antiviral activity of selected Catharanthus alkaloids. J. Pharm. Sci., 57(12):2174-2175.

Griesbach, R.J. and Bhat, R.N. (1990). Colchicine-induced polyploidy in Eustoma grandiflorum. HortScience, 25(10):1284-1286.

Henny, R.J.; Holm, J.R.; Chen, J. and Scheiber, M. (2009). In vitro induction of tetraploids in Dieffenbachia "Star Bright M-1" by colchicine. HortScience, 44(3): 646-650.

Hilu, K.W.(1993). Polyploidy and the evolution of domesticated plants. Am. J. Bot., 80(12):1494-1499.

Holdsworth, D.K. (1990). Traditional medicinal plants of Rarotonga, Cook Islands part I. Int. J. Crude Drug Res., 28(3):209-218.

Iannicelli, J.; Elechosa, M.A.; Juárez, M.A.; Martínez, A.; Bugallo, V.; Bandoni, A.L.; Escandóna, A.S. and Van Baren, C.M.(2016). Effect of polyploidization in the production of essential oils in Lippia integrifolia. Ind. Crops Prod., 81:20-29.

Jaskani, M.J.; Kwon, S.W. and Kim, D.H. (2005). Comparative study on vegetative, reproductive and qualitative traits of seven diploid and tetraploid watermelon lines. Euphytica., 145(3):259-268.

Kadota, M. and Niimi, Y. (2002). In vitro induction of tetraploid plants from a diploid Japanese pear cultivar (Pyrus pyrifolia N. cv. Hosui). Plant Cell Rep., 21(3): 282-286.

Kumar, G. and Dwivedi, K. (2014). Induced polyploidization in Brassica campestris L. (Brassicaceae). Cytol. Genet., 48(2):103-110. 
Levêque, D.; Wihlm, J. and Jehl, F. (1996). Pharmacology of Catharanthus alkaloids. Bull. Cancer, 83(3):176-186.

Levin, D.A. (2002). The Role of Chromosomal Change in Plant Evolution. Oxford University Press, New York, NY.

Marzougui, N.; Anissa, B.; Ines, T.; Walid, E.; Ferdaous, G. and Ali, F. (2011). Polyploidy induction of Tunisian Trigonella foenum-graecum L. populations. African J. Biotechnol., 10(43): 8570-8577.

Mishra, P.; Uniyal, G.C.; Sharma, S. and Kumar, S. (2001). Pattern of diversity for morphological and alkaloid yield related traits among the periwinkle Catharanthus roseus accessions collected from in and around Indian Subcontinent. Genet. Resour. Crop Evol., 48(3):273-286.

Oates, K.M.; Ranney, T.G. and Touchell, D.H. (2012). Influence of induced polyploidy on fertility and morphology of Rudbeckia species and hybrids. HortScience, 47(9):1217-1221.

Petersen, K.K.; Hagberg, P. and Kristiansen, K.(2003). Colchicine and oryzalin mediated chromosome doubling in different genotypes of Miscanthus sinensis. Plant Cell. Tissue Organ Cult.,73(2):137-146.

Ramsey, J. and Schemske, D.W. (1998). Pathways, mechanisms, and rates of polyploid formation in flowering plants. Ann. Rev. Ecol. Syst., 29(1):467-501.

Ramsey, J. and Schemske, D.W. (2002). Neopolyploidy in flowering plants. Ann. Rev. Ecol. Syst., 33(1):589-639.

Randolph, L.F. (1941). An evaluation of induced polyploidy as a method of breeding crop plants. Am. Nat., 75(759):347-363.

Rose, J.B.; Kubba, J. and Tobutt, K.R. (2000). Induction of tetraploidy in Buddleia globosa. Plant Cell. Tissue Organ Cult., 63(2):121-125.
Sajjad, Y.; Jaskani, M.; Mehmood, A.; Ahmad, I. and Abbas, H. (2013). Effect of colchicine on in vitro polyploidy induction in African marigold (Tagetes erecta). Pakistan J. Bot., 45(3):12551258

Shao, J.; Chen, C. and Deng, X. (2003). In vitro induction of tetraploid in pomegranate (Punica granatum). Plant Cell, Tissue and Organ Cult.,75(3):241246.

Thao, N.T.P.; Ureshino, K.; Miyajima, I.; Ozaki, Y. and Okubo, H. (2003). Induction of tetraploids in ornamental Alocasia through colchicine and oryzalin treatments. Plant Cell, Tissue and Organ Cult., 72(1):19-25.

Tharawoot, T.; Samyam, W. and Vessabutr, S. (2012). Colchicine induced polyploidy of in vitro Impatiens patula Craib. Thai J. Bot., 4(Special Issue):75-80.

Udall, J.A. and Wendel, J.F. (2006). Polyploidy and crop improvement. Crop Sci., 46(Supplement_1): S-3-S-14.

Väinölä, A., (2000). Polyploidization and early screening of Rhododendron hybrids. Euphytica, 112(3):239-244.

Van Der Heijden, R.; Jacobs, D.I.; Snoeijer, W.; Hallard, D. and Verpoorte, R. (2004). The Catharanthus alkaloids: Pharmacognosy and Biotechnology. Curr. Med. Chem., 11(5):607-628.

Xing, S.H.; Guo, X.B.;Wang, Q.; Pan, Q.F.; Tian, Y.S.;Liu, P.; Zhao, J.Y.; Wang, G.F.; Sun, X.F. and Tang, K.X. (2011). Induction and flow cytometry identification of tetraploids from seedderived explants through colchicine treatments in Catharanthus roseus (L.) G. Don. J. Biomed. Biotechnol., https://doi.org/10.1155/2011/793198.

Zhang, Z.; Dai, H.; Xiao, M. and Liu, X. (2008). In vitro induction of tetraploids in Phlox subulata L. Euphytica, 159(12):59-65. 


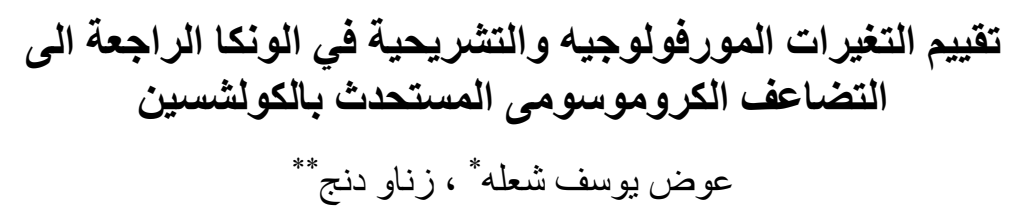

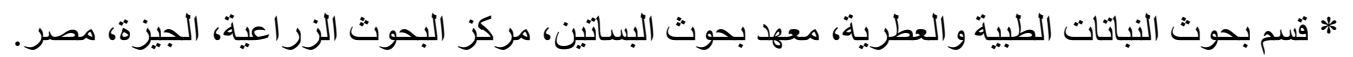

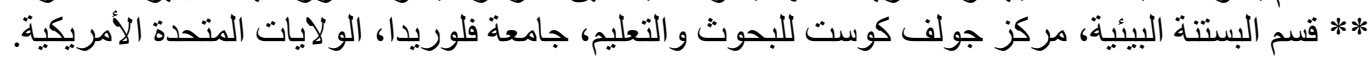

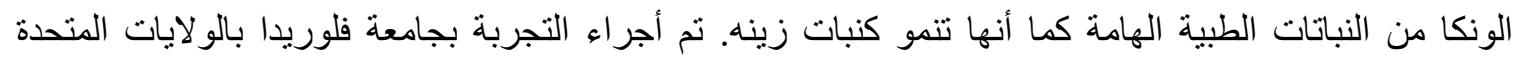

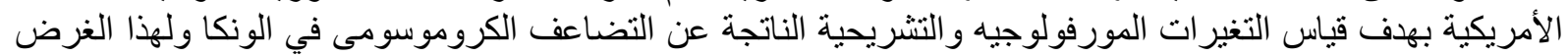

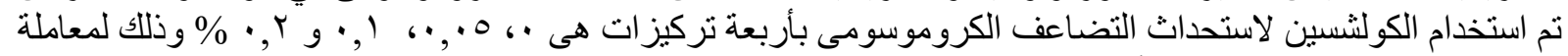

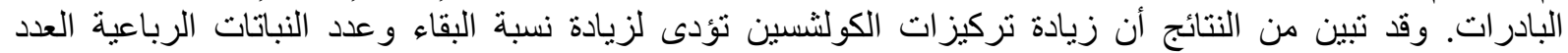

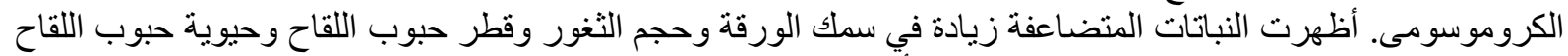

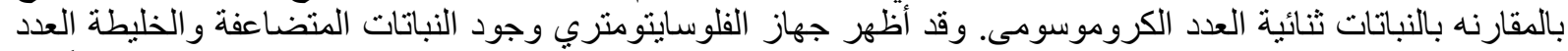

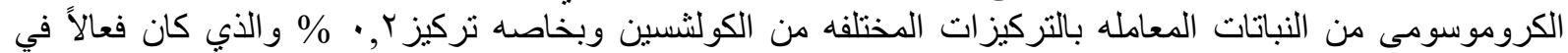

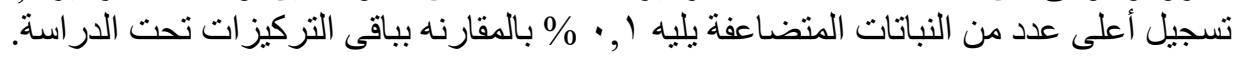

